\title{
The History and Development Trend of China's Sports Industry Policy
}

\author{
Xinhuan Zhan \\ School. of PE, Jiangxi University of finance and economics \\ Nanchang, China \\ jxsdzxh@yahoo.com.cn
}

\begin{abstract}
History of the sports industry policies in China have roughly undergone three stages. In the history, sports industry policies in China has met a sery of problem, such as the policy goal is hollow, unspecific and undefined; the policies lack pertinence. The reasons for the problems in the policies of sports industry in China are complicated. They involve the factor of sports management system, the factors of policy orientation and value orientation of government, and the factor of interest game between the subject bodies and object bodies in the process of making, implementing and transmitting policies. The introduction of $<$ The Guidance for Accelerating the Development of Sports Industry> has solved the lack of government policy support in sports industry development for a long time, and marks a significant shift that Chinese sports industry will be dominated by the state and jointly promoted by all departments and the whole society.
\end{abstract}

Keywords- Sports industry; Policies; China; History; Development trend

\section{INTRODUCTION}

The reform of the sports system in China has entered a new development phase since the Beijing Olympic Games, against the backdrop of adopting scientific approach to promote sports, improving the national system and accelerating sports reform, the call for vigorous development of sport industry has become increasingly louder, the problems caused by mismatching, absence, and overstepping of the sports industry policies have been focuses of attention of the whole society.

\section{HISTORICAL REVIEW OF THE SPORTS INDUSTRY POLICIES IN CHINA}

The industrial policy is a collection of policies worked out by the central or local governments to actively intervene the industrial economic activities. And its functions including remedy market failure and allocate resources efficiently; protect weak national industry; buffer economic upheaval; bring into play the "second-mover" advantages and strengthen adaptive capacity. The research, formulation and promulgation of the sports industry policies in China have roughly undergone three stages.

During the first stage (1978-1992), the sports industry took the experience gained at one unit and popularized it in a whole area and it was in the preparatory and starting phase extending from one aspect to many. The focal point of the policy is to encourage qualified public institutions to transform from conventional to enterprising, implement diversified operation, expand scope of services and positively increase revenue and reduce expenditure; to attract social funds in the form of sponsorship and joint operation to support sports competition activities and build high-level sports team, so as to relieve the issue of development fund shortage.

The second phase (1992-1997): the phase of the exploration and practice of national sports industry policies and the sports policies with industry attribute became bright and clear. The sports industry policies at this phase can be fallen into the following categories: the policies establishing the position of sports industry; the sports industry development policies related to the reform of Chinese sports cause; policies regarding sports industry or other sector.

For instance, The Development Guidelines for the Sports industry (1995-2010) released by State Physical Culture and Sports Commission on June 16, 1995 pointed out that economic policies for sports industry should be drawn and improved to offer necessary support for the development of the sports industry.

The third phase (1997- ): the national sports industry policies become clear-cut and local governments further explore the sports industry policies, and preliminary results were achieved in this phase. During this period, overall planning policies regarding the sports industry development were formulated and specialized sports industry policies became increasingly mature.

On March 24, 2010, General Office of the State Council issued The Guidance for Accelerating the Development of Sports Industry and further put forward the idea that the acceleration of the development of the sports industry plays an important role in extending the development space of the sports industry, promoting China's transformation from a large country of sports to a sports power and enhancing the economic and social development in a harmonious manner.

\section{THE PROBLEMS OF THE SPORTS INDUSTRY POLICIES IN CHINA}

We have to improve the implement achievements of our sports industry policies, and the major problems involve:

Firstly, the policy goal is hollow, unspecific and undefined. And it is macroscopic and full of slogan words with inconspicuous requirement and in lack of a sub-goal system matched with the general goal and a short-term goal matched with a long-term goal.

Secondly, the policies lack pertinence. The existing sports industry polices in China mechanically apply the 
policies used in other industries, which is inadequate to reflect the characteristics and rules of our sports industry.

Thirdly, the value standard of the sports industry policies deviates from the constraint condition. Due to the historical background when the policies were made, many sports economic activities stick to the principle of "No arguments, brave trials", as a result a process of policy trial and error is unavoidable and many unscientific and unreasonable policies may be adopted in a specified period of time.

Fourthly, policies lack continuity and stability. Many policies are makeshifts produced by governments' crisis public relations. And the policies cannot be set as laws and regulations make them lack continuity and stability, which is prone to lead to short-sighted acts.

\section{THE PROBLEMS AND CAUSES OF THE SPORTS INDUSTRY POLICIES IN CHINA}

The reasons for the problems in the policies of sports industry in China are complicated. They involve the factor of sports management system, the factors of policy orientation and value orientation of government, and the factor of interest game between the subject bodies and object bodies in the process of making, implementing and transmitting policies.

Firstly, in the process of Chinese economic system reform, the reform of economic system, more often than not, falls behind that of other departments, which results in a fact that the industrialization and market developing degree of Chinese sports market is at a low level.

Since the market mechanism is relatively less mature, Chinese sports industry policies mostly rely on administrative means. Moreover, the legislative sports industry polices are inadequate. All these elements mentioned above give rise to the lack of continuity and stability in terms of Chinese sports industry policies.

Secondly, the policy makers and researchers of Chinese sports industry often fall into a trap that the sports industry needs desperately to strengthen the regulating effects of industry policies. In fact, the core contents are the regulation of government on economic structure and the choice of industry development paths.

Its existence relies on a series of strict limited conditions. However, a widespread problem that the government controls too much and imposes more restrictions on the market is evident in China.

Thirdly, the policy transmission process of sports industry is very important. And the disorder of Chinese sports administration system leads to a fact that policy transmission chain of Chinese sports industry is too long and complicated.

Moreover, because the policy transmission involves many parties, such as, the central government, the department, industry associations, local governments and enterprises, etc, who have different interest orientations, many invisible non-cooperation behaviors appear.

\section{THE DEVELOPMENT TREND OF THE SPORTS INDUSTRY POLICIES IN CHINA}

The introduction of <The Guidance for Accelerating the Development of Sports Industry> has solved the lack of government policy support in sports industry development for a long time, and marks a significant shift that Chinese sports industry will be dominated by the state and jointly promoted by all departments and the whole society.

Firstly, the sports market will be opened gradually. The future direction of Chinese economic system reform is the gradual improvement of the socialist market economic system in order to make market play a more important role of distributing resources in the economic life. Because the sports industry policies should be in accordance with the economic system, the policy improvement direction of Chinese sports industry should be aimed at making market play the dominant role in distributing sports resources in order to fully exploit the economic function of sports.

The government shifts from the direct intervention in the sports market to the guidance and support for the development of sports industry, strives to construct an orderly and prosperous sports market and a sports industry system focusing on sports service industry with extensive ranges and reasonable structure and forms a pattern in which various ownerships coexist and various economic sectors compete, participate and jointly promote the sports industry.

Secondly, it needs to increase policy support. The government will expand the capital source channels of the sports industry development and support the development of sports industry through a variety of ways, including: supporting the qualified sports companies to raise funds in the capital market, raising development funds by issuing bonds and shares, raising project fund, reconstructing funds and exchanging stock, encouraging private and foreign capitals to invest in sports industry and build sports facilities, encouraging financial institutions to adapt to the needs of sports industry development, develop new products and new businesses, encouraging the social donations and construction of sports foundation, encouraging the organizations and individuals at home and abroad to donate to sports foundation and giving relevant preferential policies of business income tax to qualified and non-profitable sports organizations based on relevant provisions of tax laws.

Thirdly, it needs to support and regulate the professional sports development. The professional sport is one of the important organizations in sports industry. Exploring actively the professional sports development with Chinese characteristics is of great and positive significance to expanding the channels of sports development, expanding the public participation and developing popular sports.

Chinese professional sports represented by the Football League did not achieve the expected results after over 10 years of development. Therefore, the government has to improve policies, rules and management systems of professional sports gradually, strictly operate the access and operation supervision of professional sports clubs, support the construction of professional sports clubs, improve the 
professional league system and constantly improve the level of professional sports.

Fourthly, it needs to promote the base construction of national sports industry. Since April, 2006, the State General Sports Administration has approved Shenzhen, Wenjiang in Chengdu, Jinjiang in Fujian, Longtanhu in Beijing and Fuyang in Zhengjiang of constructing national sports industry bases. The construction of these national sports industry bases has acquired the support and encouragement from local governments and relevant preferential policies.

Taking into consideration the present effects, the construction of sports industry bases has attracted many market resources, like competitive companies, competitive projects and funds and the talents to gather around the sports industry bases and played important roles in promoting the structure optimization and upgrading of local industries and further promoting local economic and social development. In the future, more sports industry bases will be developed well under the policy support of the state and local governments.

\section{REFERENCES}

[1] DONG Jie. Economic impact of Olympic Games to the host city, [J]Chinese Journal of Sports Science and Technical, 2004, (1),p34-37.

[2] Gregory Mankiw. Principle of economics. [M]San Lien Press, 2001, p122-128

[3] YU Jian, Politics, Economical, and Cultural Affect of 2008 Beijing Olympic Games to Contemporary China, [J]Journal of Shandong Sports University, 2002, (3),p12-15.

[4] J. Clerk Maxwell, A Treatise on Electricity and Magnetism, 3rd ed., vol. 2. Oxford: Clarendon, 1892, pp.68-73.

[5] G. Eason, B. Noble, and I. N. Sneddon, "On certain integrals of Lipschitz-Hankel type involving products of Bessel functions," Phil. Trans. Roy. Soc. London, vol. A247, pp. 529-551, April 1955.

[6] J. Clerk Maxwell, A Treatise on Electricity and Magnetism, 3rd ed., vol. 2. Oxford: Clarendon, 1892, pp.68-73.

[7] I. S. Jacobs and C. P. Bean, "Fine particles, thin films and exchange anisotropy," in Magnetism, vol. III, G. T. Rado and H. Suhl, Eds. New York: Academic, 1963, pp. 271-350.

[8] Y. Yorozu, M. Hirano, K. Oka, and Y. Tagawa, "Electron spectroscopy studies on magneto-optical media and plastic substrate interface," IEEE Transl. J. Magn. Japan, vol. 2, pp. 740-741, August 1987 [Digests 9th Annual Conf. Magnetics Japan, p. 301, 1982].

[9] M. Young, The Technical Writer's Handbook. Mill Valley, CA: University Science, 1989. 